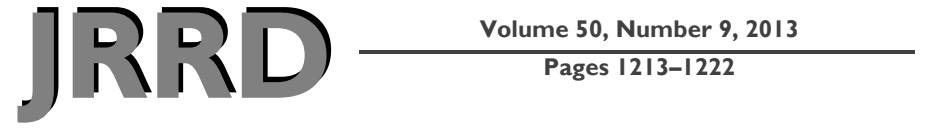

\section{Upper-limb activity in adults: Referent values using accelerometry}

\author{
Ryan R. Bailey, MSOT, OTR/L; ${ }^{1}$ Catherine E. Lang, PT, PhD ${ }^{1-2 *}$ \\ Programs in ${ }^{1}$ Physical Therapy and ${ }^{2}$ Occupational Therapy, Department of Neurology, Washington University School \\ of Medicine, St. Louis, MO
}

\begin{abstract}
The goal of physical rehabilitation following upperlimb (UL) impairment is functional restoration of the UL for use in daily activities. Because capacity for UL function may not translate into real-world activity, it is important that assessment of real-world UL activity be used in conjunction with clinical measures of capacity. Accelerometry can be used to quantify duration of UL activity outside of the clinic. The purpose of this study was to characterize hours of UL activity and potential modifying factors of UL activity (sedentary activity, cognitive impairment, depressive symptomatology, additive effects of comorbidities, cohabitation status, and age). Seventy-four community-dwelling adults wore accelerometers on bilateral wrists for $25 \mathrm{~h}$ and provided information on modifying factors. Mean time of dominant UL activity was $9.1+/-1.9 \mathrm{~h}$, and the ratio of activity between the nondominant and dominant ULs was $0.95+/-0.06 \mathrm{~h}$. Decreased hours of dominant UL activity was associated with increased time spent in sedentary activity. No other factors were associated with hours of dominant UL activity. These data can be used to help clinicians establish outcome goals for patients given preimpairment level of sedentary activity and to track progress during rehabilitation of the ULs.
\end{abstract}

Key words: accelerometry, arm activity, capacity, cognitive impairment, depression, function, real-world activity, referent data, sedentary activity, upper-limb activity.

\section{INTRODUCTION}

Upper-limb (UL) impairment from illness or injury results in significant financial and functional deficits, many of which have long-lasting consequences. Workers' compensation claims for UL injuries exceed $\$ 500$ million per year in the United States [1]. Hemiparesis following stroke, a condition that affects the ULs, contributes to increased mortality and Medicare costs [2]. For individuals with severe rheumatoid arthritis (RA), another condition that affects the ULs, the cumulative cost per patient per decade approaches \$200,000 [3]. Actual costs of UL impairments are likely much higher when indirect costs, such as loss of work time, psychological stress, and increased likelihood of repeated injury, are considered [4-6]. Functional deficits of traumatic UL injury result in decreased independence in activities of daily living (ADLs) and decreased quality of life that can persist from 1 to 4 yr postinjury [5,7]. Disability in ADLs because of hemiparesis following stroke persists beyond 6 mo in 54 percent of people who participate in inpatient rehabilitation [8], and functional capacity decreases over time in persons with RA [9]. Effective rehabilitation of the ULs following impairment can improve functional outcomes, assist people in returning to gainful employment, and reduce costs.

\footnotetext{
Abbreviations: $\mathrm{ADL}=$ activity of daily living, $\mathrm{MET}=$ metabolic equivalent, $\mathrm{NIH}=$ National Institutes of Health, $\mathrm{RA}=$ rheumatoid arthritis, $\mathrm{UL}=$ upper limb.

*Address all correspondence to Catherine E. Lang, PT, PhD; Program in Physical Therapy, Washington University School of Medicine, 4444 Forest Park Ave, Campus Box 8502, St. Louis, MO 63108-2212; 314-286-1945; fax: 314286-1410. Email: langc@wustl.edu http://dx.doi.org/10.1682/JRRD.2012.12.0222
} 
Paramount to effective UL rehabilitation is appropriate assessment of UL function within the clinic and outside in the real-world environment. A common assumption is that increased capacity for UL function, as measured by clinical assessments (e.g., Jebsen-Taylor Hand Function Test, Action Research Arm Test, etc.), translates into increased real-world functional activity. There is an absence of data, however, to support this assumption. In inpatient settings, increased capacity did not result in improved performance outside of therapy sessions [10]. Likewise, in outpatient settings, clinical assessment of capacity (e.g., Functional Capacity Evaluation) was only weakly associated with economic predictors of return to work [11]. Clinical assessments may not accurately measure real-world performance, which is the outcome of most interest when the goal is functional recovery. In order to measure real-world performance, additional tools are necessary to assess UL function outside the clinic in an objective and reliable way. One such tool is the accelerometer.

Accelerometry can be used as an index of UL activity, defined as movement of the UL outside the clinic to complete functional and nonfunctional tasks. Accelerometry has been used to quantify hours of UL activity in individuals with stroke during inpatient and outpatient rehabilitation $[10,12-14]$. The validity and reliability of accelerometers to measure UL activity is well-established and correlates well with tests of UL function [12-13,15-19]. Furthermore, accelerometry is a useful substitute for self-report measures because it can reduce or eliminate reporting biases associated with self-report [20-21].

The technology now exists to track UL activity in patients as they undergo rehabilitation, but data on UL activity from a referent sample of adults have not yet been gathered. Some data on UL activity are available, but sample sizes have been small [17,22-23] and limited to nondisabled participants aged 65 to 78 yr [10,22,24]. Furthermore, there has been no investigation or control for factors that may influence UL activity. Studies have examined general physical activity by using hip-worn accelerometers as participants go about their day-to-day activities. Known factors associated with decreased general physical activity include increased time spent in sedentary activity [25-26], cognitive impairment [27], depression [28], additive effects of comorbidities [29-30], and increased age [31-32]. Additionally, the association between living alone and decreased general physical activity is inconclusive [32-35]. These same factors, which are often present in the rehabilitation population, may also influence UL activity; their association with duration of UL activity needs to be explored.

The purpose of this study, therefore, was to characterize hours of UL activity and potential modifiers of UL activity in a comprehensive sample of adults. We sampled a broad range of ages because UL impairment is a consequence of many conditions that affect adults of all age. We hypothesized that decreased hours of UL activity would be associated with increased time spent in sedentary activity, severity of cognitive impairment, depressive symptomatology, number of comorbidities, and older ages. We also hypothesized that hours of UL activity would be greater in participants living alone. Referent data on hours of UL activity that account for the effect of modifying factors will provide clinicians with targeted values of UL activity for individual patients given their unique preimpairment demographic, social, and health characteristics. Overall, these data will help clinicians and patients set rehabilitation goals as well as track progress during rehabilitation of the ULs following impairment.

\section{METHODS}

\section{Participants}

We recruited 74 community-dwelling adults from the St. Louis metropolitan area through a community-based recruitment organization. Participants were enrolled who were age $30 \mathrm{yr}$ and older and able to follow commands. Participants were excluded if they had a self-reported history of a neurological condition or physical impairment of the UL. The Human Research Protection Office of Washington University approved the protocol for this study. Informed consent was obtained from all participants prior to data collection.

\section{Study Protocol}

This cross-sectional study was conducted at the Neurorehabilitation Laboratory at Washington University School of Medicine, as well as in the homes of study participants. Participants attended a $1 \mathrm{~h}$ office visit during which they provided demographic information and social and medical histories and completed self-report questionnaires on general physical activity, cognition, and depressive symptomatology. Next, accelerometers were placed on both wrists proximal to the head of the ulna to ensure capture of distal movement that might occur when more proximal joints were maintained relatively still (e.g., during writing). 
Participants were asked to wear the accelerometers for the subsequent $25 \mathrm{~h}$, including during sleep, while they went about their typical daily routine.

Periods of sleep were included for several practical reasons. First, in order for accelerometry to be used by busy clinicians, analyzing data must be a user-friendly and efficient process. Tight schedules limit clinicians' ability to identify and subtract sleep time from accelerometry output. Second, deciding what constitutes nonfunctional movement (e.g., a tick or jerk) during quiescent periods is subjective. Movement during a nap or nighttime may be associated with functional movements such as an unconscious scratch or reaching for a glass of water and would be lost if they were removed because the subject was "asleep." Third, asking participants to remove the accelerometers during sleep would have increased the likelihood that participants would forget to replace them upon waking.

We chose $25 \mathrm{~h}$ because this time period has been used in previous studies $[17,23]$ and was a practical compromise between sufficient wearing time and participant willingness to wear the accelerometers. A subset $(n=5)$ of participants wore the accelerometers for a second $25 \mathrm{~h}$ period, separated by at least $1 \mathrm{wk}$, and demonstrated that UL activity values were reliable (intraclass correlation coefficient $\left._{(3, \mathrm{k})}=0.93, p=0.01\right)$ and a good estimate of UL activity during an average day. At the conclusion of the $25 \mathrm{~h}$ period, participants were queried to ensure that the accelerometers were worn for the entire period. Additionally, accelerometry data were visually inspected to verify that participants wore the accelerometers for $25 \mathrm{~h}$.

\section{Measures}

The primary outcome measure was hours of UL activity as determined by accelerometry data. Wireless accelerometers (GT3X+ Activity Monitor, ActiGraph; Pensacola, Florida) were used to quantify the duration of UL movement that occurred during the wearing period. The GT3X+ Activity Monitor contains a tri-axis, solid state digital accelerometer that detects acceleration in three planes. The accelerometer is small $(4.6 \times 3.3 \times$ $1.5 \mathrm{~cm})$, waterproof, sensitive to -6 to $+6 g$-force, and contains $512 \mathrm{MB}$ of internal storage. Acceleration was sampled at $30 \mathrm{~Hz}$. The amount of acceleration that occurs per sample is measured in activity counts $(0.001664 g /$ count). For individual axes, sample activity counts were integrated for each second of data. Next, for each second of data, activity counts across the three axes were combined into a single value, called a vector magnitude, using the following equation: $\sqrt{ }\left(x^{2}+y^{2}+z^{2}\right)$. Using a technique similar to that described by Uswatte et al. [14], seconds when the vector magnitude was $\geq 2$ were categorized as "movement." Seconds when the vector magnitude was $<2$ were categorized as "nonmovement." Seconds of movement were summed to determine hours of UL activity for the dominant and nondominant ULs. Percentage of UL activity was calculated by dividing the hours of UL activity by length of time the accelerometers were worn. The ratio of hours of UL activity between the nondominant and dominant ULs was also calculated.

Predictor variables believed to potentially modify UL activity included time spent in sedentary activity, cognitive impairment, depressive symptomatology, number of comorbidities, cohabitation status, and age.

Sedentary activity was measured using levels A and B of the Physical Activity Scale [36], a self-report measure that quantifies general physical activity during a typical $24 \mathrm{~h}$ weekday. Activities are grouped into nine levels that represent differing activity intensities measured by metabolic equivalents (METs). Time spent in levels A (0-0.9 METs) and B (1.0-1.4 METs) were summed to determine time spent in sedentary activity, and activities included sleeping, reading, watching television, listening to music, and meditating. The Physical Activity Scale is strongly correlated with activity measured by activity diary $(r=0.74, p<0.01)$ [36].

Cognitive impairment was measured using the Short Blessed Test, a test of cognitive function that screens for impairment in memory, orientation, and concentration. Errors on 6 items are scored and weighted, with a total possible score of 28. Scores of 0 to 4 indicate normal cognition, 5 to 9 indicate questionable impairment, and 10 or more indicate impairment consistent with dementia [37-38].

Depressive symptomatology was measured using the Center for Epidemiological Studies-Depression Scale, which characterizes depressive symptomatology in the general population. Twenty items are scored on a 4-point Likert scale (total score $=60$ ). Higher scores indicate greater depressive symptomatology [39-41].

Number of self-reported comorbidities was obtained via self-report using a checklist of common medical conditions. Checklists improve memory recall of health conditions relative to open- and free-response methods [4243]. The number of comorbidities was used as a potential modifier of UL activity instead of specific conditions 
because the additive effect of comorbidities was the factor of interest [29-30].

Cohabitation status, obtained from the social history, determined if participants lived alone or with other people.

Age, obtained from a demographic questionnaire, was our final predictor variable. Additional descriptive information was also collected according to routine laboratory procedures (e.g., demographics, handedness, etc.).

\section{Data Analyses}

Data were downloaded from each accelerometer and subsequently processed using MATLAB R2011B (MathWorks; Natick, Massachusetts) software. A custom-written program was used to dichotomize each second of accelerometry data into periods of movement or nonmovement and to calculate hours of UL activity, percentage of UL activity, and ratio of UL activity.

Statistical analyses were performed using IBM SPSS Statistics 19 (Armonk, New York), and the criterion for statistical significance was $p<0.05$. Descriptive statistics of each variable of interest were computed. Predictor variables were assessed for normality using KolmogorovSmirnov tests. Examination of residuals was performed visually as well as using Cook's distance. Time spent in sedentary activity and depressive symptomatology scores were log-transformed because they were right-skewed. Pearson correlation analyses were used to examine relationships between the outcome variable and continuous predictor variables. Cognitive impairment scores and number of comorbidities violated the parametric assumption of a normal distribution despite log-transformation, and Spearman correlation analyses were used. Based on our sample size, correlation coefficients greater than 0.24 were significant at $p<0.05$ and coefficients greater than 0.30 were significant at $p<0.01$. Correlation coefficients of 0.60 and higher were considered to be strong, between 0.30 and 0.59 were moderate, and 0.29 and lower were weak [44]. Mann-Whitney U was used to examine the difference in UL activity between participants who were and were not working. A paired samples $t$-test was used to examine differences in hours of UL activity between participants based on hand dominance, and an independent samples $t$-test was used to examine differences in hours of UL activity based on cohabitation status.

\section{RESULTS}

Demographic information and categorical predictor variables are presented in Table 1. Because there was no difference in hours of dominant UL activity between participants not working $(9.1 \pm 2.0 \mathrm{~h})$ and the participants who were working $(9.0 \pm 2.1 \mathrm{~h}, p=0.83)$, all participants were grouped together for subsequent analyses. All participants wore the accelerometers for the entire recording period (mean $25.0 \mathrm{~h}$, range: $24.3-26.0 \mathrm{~h}$ ). No technical problems with the accelerometers were reported.

Descriptive statistics of outcome variables and remaining continuous predictor variables are reported in Table 2 . Hours of dominant UL activity were greater than hours of nondominant UL activity ( $p<0.001)$, though the absolute difference between limbs was only $30 \mathrm{~min}$. Because Pearson correlations were excellent between dominant and nondominant UL activity, between dominant and nondominant percent of UL activity, and between UL activity and percent of UL activity (for all values, $r \geq 0.96, p<0.001$ ), dominant UL activity was selected as the outcome variable for analyses of potential modifiers. The variability of the ratio of UL activity was very small despite a large range in

Table 1.

Demographic information and categorical predictor variables.

\begin{tabular}{lc}
\hline \multicolumn{1}{c}{ Variable } & Value \\
\hline Age $(y r)$ & $54 \pm 11$ \\
Mean \pm Standard Deviation & $30-83$ \\
Range & \\
Sex & $35(47 \%)$ \\
Male & $39(53 \%)$ \\
Female & \\
Race & $30(40 \%)$ \\
White & $44(60 \%)$ \\
African American & \\
Hand Dominance & $62(84 \%)$ \\
Right & $12(16 \%)$ \\
Left & \\
Work Status & $62(84 \%)$ \\
Not Working & $7(10 \%)$ \\
$<20$ h/wk & $4(5 \%)$ \\
Part-Time & $1(1 \%)$ \\
Full-Time & \\
Cohabitation Status & $27(36 \%)$ \\
Lives Alone & $47(64 \%)$ \\
Lives with Others & \\
\hline \hline
\end{tabular}


Table 2.

Mean, standard deviation (SD), and range of outcome variable and other predictor variables.

\begin{tabular}{lcc}
\hline \multicolumn{1}{c}{ Variable } & Mean \pm SD & Range \\
\hline Hours of UL Activity & & \\
$\quad$ Dominant & $9.1 \pm 1.9$ & $4.4-14.2$ \\
$\quad$ Nondominant & $8.6 \pm 2.0$ & $4.1-15.5$ \\
$\quad$ Ratio (nondominant/dominant) & $0.95 \pm 0.06$ & $0.79-1.1$ \\
Percent of UL Activity & & \\
$\quad$ Dominant (\%) & $36.2 \pm 7.8$ & $17.7-56.8$ \\
$\quad$ Nondominant (\%) & $34.5 \pm 8.0$ & $16.5-61.9$ \\
Sedentary Activity ${ }^{*}(\mathrm{~h})$ & $11.8 \pm 2.7$ & $7-20$ \\
Cognitive Impairment & $2.0 \pm 2.9$ & $0-10$ \\
Depressive Symptomatology & $8.9 \pm 7.8$ & $0-35$ \\
Number of Comorbidities & $1.4 \pm 1.5$ & $0-6$ \\
${ }^{*}$ Determined by self-report. & & \\
UL = upper limb. & & \\
\hline \hline
\end{tabular}

hours of UL activity (Table 2). Figure 1 illustrates the absence of a relationship between hours of dominant UL activity and the ratio of UL activity $(r=0.08, p=0.51)$.

Hours of dominant UL activity were moderately correlated with time spent in sedentary activity (Figure 2(a), $r=-0.36, p<0.01)$. Correlations for hours of dominant $\mathrm{UL}$ activity versus cognitive impairment $(\rho=0.20, p=$ 0.09), depressive symptomatology (Figure 2(b), $r=0.11$, $p=0.37)$, number of comorbidities $(\rho=-0.12, p=0.32)$, and age (Figure 2(c), $r=-0.002, p=0.99$ ) were not significant. There was no difference in hours of dominant UL activity based on cohabitation status $(p=0.85)$. Secondary analyses indicated that there was no association between the ratio of UL activity and sedentary activity, cognitive impairment, depressive symptomatology, number of self-reported comorbidities, and age (for all values, $r$ and $\rho<0.13, p>0.27$ ).

\section{DISCUSSION}

Hours of UL activity during a typical day for community-dwelling adults was quantified using accelerometry in this study. Mean UL activity was $9.1 \pm 1.9 \mathrm{~h}$ and $8.6 \pm$ $2.0 \mathrm{~h}$ for dominant and nondominant ULs, respectively. The ratio of UL activity $(0.95 \pm 0.06)$ indicates that the duration of UL activity between limbs was roughly equal, though quality of movements likely differed between limbs (e.g., stabilizing a bowl with one hand while stirring with the other hand). Potential modifiers of UL activity

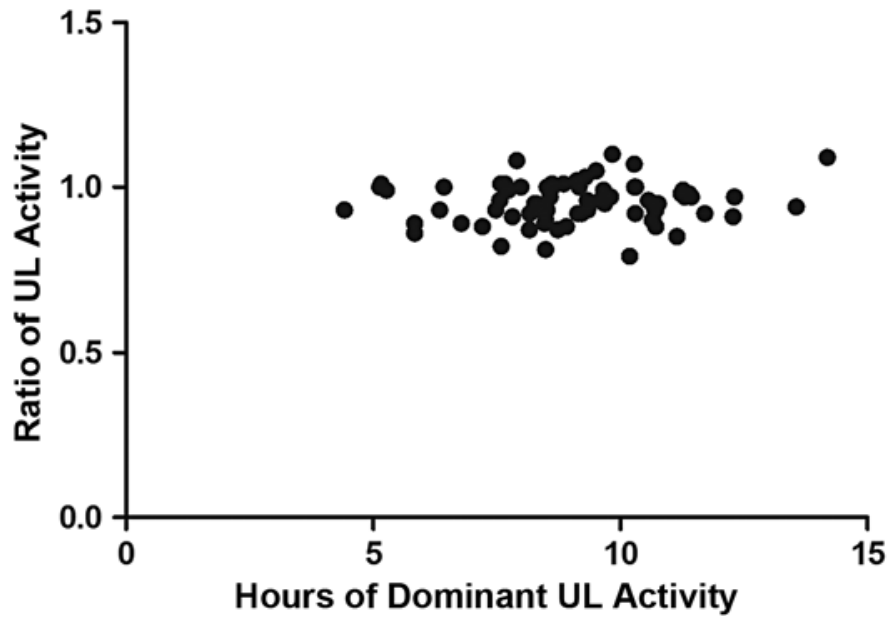

Figure 1.

Scatterplot of ratio of upper-limb (UL) activity vs hours of dominant UL activity. Despite variability in hours of dominant UL activity, duration of activity between limbs is roughly equal, as indicated by narrow range in ratio of UL activity.

were examined for their association with hours of UL activity. In accordance with one of our hypotheses, decreased hours of UL activity was associated with increased time spent in sedentary activity. Hours of UL activity, however, was not associated with cognitive impairment, depressive symptomatology, number of comorbidities, or age, nor was there a difference in hours of UL activity between participants living alone versus with others.

These referent data build on previous studies that quantified the amount of arm activity in smaller samples of nondisabled, older adults [10,22-24] by categorizing hours of UL activity in a larger sample of adults of various ages. These data also indicate that time spent in sedentary activity may influence hours of UL activity. Other factors, which one might assume could influence UL activity, did not. Our results can now be used in conjunction with measures of UL functional capacity within the clinic to help clinicians set goals for individual patients as well as to track progress during rehabilitation.

The ratio of UL activity is a valuable measure of function because it reflects activity of one limb relative to the other limb and accounts for general physical activity that affects both limbs [13]. General physical activity (e.g., walking) is accounted for because it likely affects both limbs equally [12]. A lower ratio of UL activity indicates increased asymmetry in duration of activity 


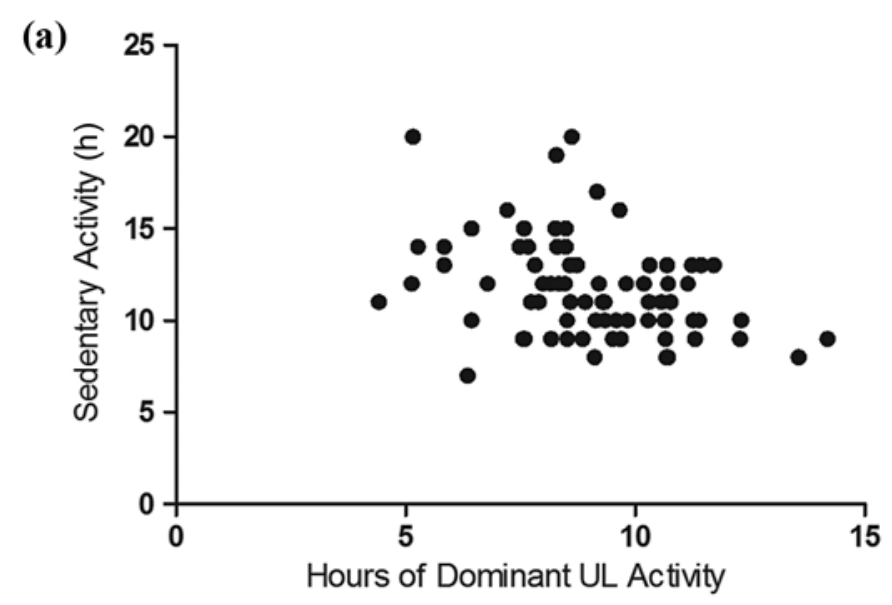

(b)

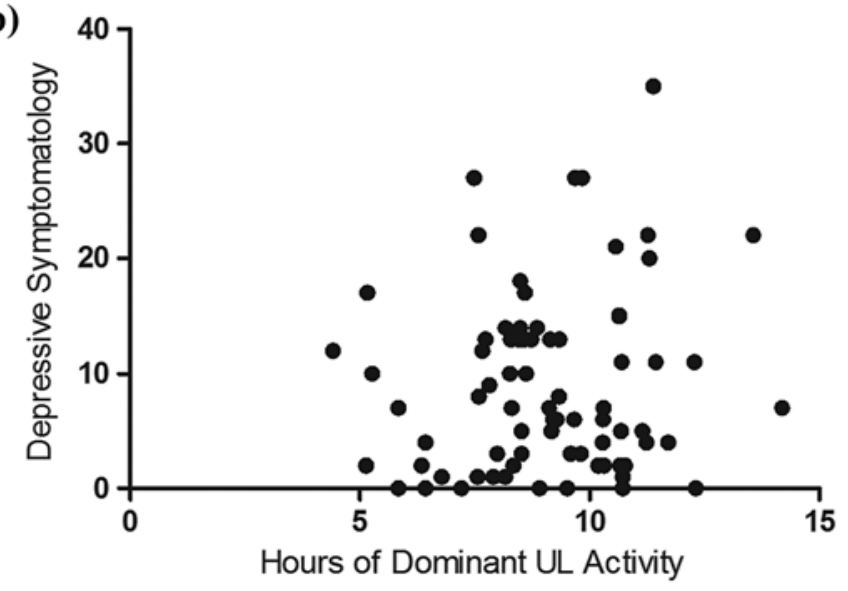

(c)

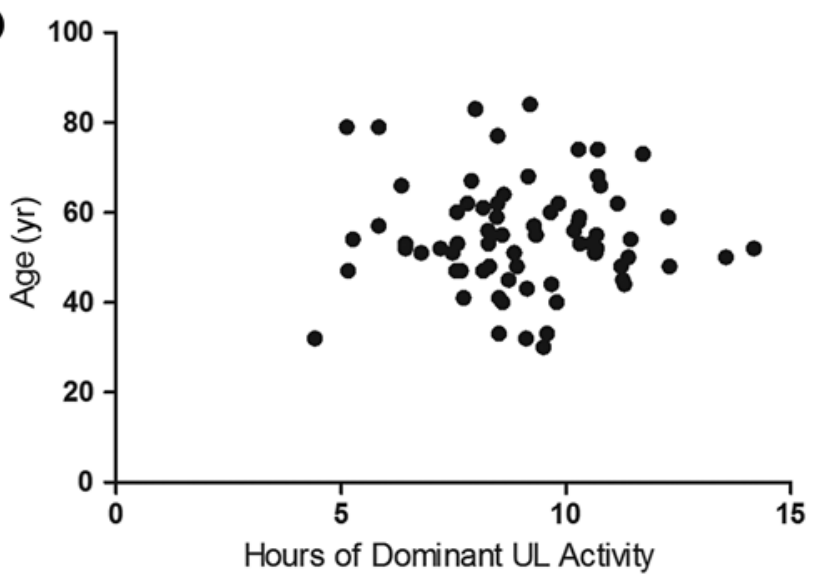

Figure 2.

Scatterplots of hours of dominant upper-limb (UL) activity vs (a) time spent in sedentary activity, (b) depressive symptomatology measured using Center for Epidemiological StudiesDepression Scale, and (c) age. Time spent in sedentary activity, but not depressive symptomatology or age, was associated with hours of UL activity. between the limbs, and in a clinical population, suggests decreased functionality of the limb in question. Our data indicate that the ratio of UL activity is a robust metric of real-world UL function in persons without UL impairment because its range and variability were relatively small in contrast with the range and variability in hours of UL activity. Additionally, the mean ratio of UL activity in our sample was similar to that in a sample of middle-aged adults (0.94) [23], and our range was similar to mean ratios reported in smaller samples of healthy, older adults $(0.79-1.17)$ [10,22,24].

Only time spent in sedentary activity was associated with hours of UL activity, despite reported associations between general physical activity and the predictor variables chosen for exploration in this study. Time spent in sedentary activity is easily measured by self-report in the clinic and could be considered when identifying a postrehabilitation target value for hours of UL activity. Individual goals for postrehabilitation hours of UL activity could be adjusted to be consistent with preimpairment levels of sedentary activity. Independent of the amount of expected or actual hours of UL activity that occurs as a result of rehabilitation, hours of UL activity of the impaired limb should be approximately 95 percent of the unimpaired UL activity when recovery has occurred, as indicated by the ratio of UL activity.

Cognitive impairment, depressive symptomatology, and number of self-reported comorbidities were not associated with hours of UL activity in our sample, even though studies show that these factors are associated with decreased general physical activity $[29,45-46]$. A possible reason for the lack of association between these factors and hours of UL activity is that our sample did not contain a wide distribution of values for some factors. The range of scores for cognitive impairment and number of comorbidities were low (Table 2). The range of scores for depressive symptomatology was larger but still not associated with hours of UL activity (Figure 2(b)). In the clinic, patients often complete assessments that screen for cognitive impairment, depression, and comorbidities. Our data suggest that low to moderate levels of cognitive impairment, depressive symptomatology, and comorbidities are not associated with hours of UL activity and may not affect postimpairment hours of UL activity.

Two additional potential modifiers were unexpectedly unrelated to UL activity. First, there was no difference in hours of UL activity between participants living alone and those living with others (Table 1). We hypothesized that 
participants living alone would have higher UL activity, possibly as a result of increased domestic demands that cannot be completed by a partner or children. The data indicate that this is not the case. This finding is consistent with two studies that show no difference in levels of general physical activity between persons living alone versus with other people [33-34], but not with two other studies $[32,35]$. Second, there was no association between hours of dominant UL activity and age. We hypothesized that decreased hours of UL activity would be associated with increased age because other studies demonstrated that decreased general physical activity is associated with increased age [31,47-48]. These disparate findings may be explained by the possibility that aging adults exchange more vigorous activities for less vigorous activities that require similar hours of UL activity. In sum, our data indicate that hours of UL activity is not associated with cohabitation status or age.

As accelerometer technology becomes more widespread, clinicians can use this tool to set specific goals, such as increasing a low ratio of UL activity or achieving a ratio of UL activity in the referent range of 0.79 to 1.1 . These data can help clinicians modify expectations of hours of UL activity based on preimpairment, selfreported time spent in sedentary activity, but not selfreported cognitive impairment or depressive symptomatology. For example, consider a patient who receives care from a hand therapist following a traumatic injury to the hand. The patient reports spending a large amount of time in sedentary activity prior to sustaining the injury. The therapist should reduce the outcome goal for hours of UL activity to less than $9 \mathrm{~h}$ because increased time spent in sedentary activity is associated with decreased UL activity. Similarly, the therapist can track the change in the ratio of UL activity over time. If the patient's initial ratio is 0.50 and increases to 0.80 , the therapist can be confident that movement of the impaired limb has increased from 50 to 80 percent of movement of the unimpaired limb during the course of rehabilitation.

Beyond the clinical implications of this study, the methods and tools used in this study will be useful for rehabilitation researchers. The use of accelerometry to measure duration of UL activity could replace assessments that require significant administration time as well as eliminate reporting biases associated with self-report questionnaires. Some manufacturers offer accelerometers that transmit real-time data, which could be used to engineer systems that provide patients feedback to enhance performance as activity occurs. Additionally, as technology continues to improve and devices become more compact, it may be possible to place accelerometers on individual digits to capture skilled finger movements.

Given the observational nature of this study, only association, not causation, between potential modifying factors and hours of UL activity can be determined. A prospective study examining the relationship between hours of UL activity and modifying factors would be necessary to determine causation. Second, the time spent in sedentary activity and number of comorbidities were obtained via self-report and may have been subject to reporting bias. Future studies could more accurately quantify time spent in sedentary activity using wristworn accelerometry once thresholds corresponding to sedentary activity have been validated. In order to accurately capture the number of comorbidities experienced by each study participant, data from participants' medical charts could be used. This was not feasible in the present study, however, because participants were recruited from the community and not from a single health organization.

A final comment is that most study participants were not employed. Patients with significant UL impairments are likely to not be working; therefore, these findings generalize well to a rehabilitation population. It is possible that UL activity may differ for individuals who work. Hours of UL activity in a working population should be determined.

\section{CONCLUSIONS}

This study reported data on hours of UL activity in a comprehensive sample of community-dwelling adults and explored the associations between hours of UL activity and factors that could have potentially modified hours of UL activity. These referent values provide objective information on real-world UL activity that has previously been available only through self-report assessments. Hours of UL activity and the ratio of UL activity reflect the amount of real-world movement that occurs outside the clinic and can be used by clinicians in conjunction with clinical assessments of UL function to set outcome goals and evaluate treatment progress for rehabilitation of the ULs. 


\section{ACKNOWLEDGMENTS}

\author{
Author Contributions: \\ Study concept and design: R. R. Bailey, C. E. Lang. \\ Acquisition of data: R. R. Bailey. \\ Analysis and interpretation of data: R. R. Bailey, C. E. Lang. \\ Drafting of manuscript: R. R. Bailey, C. E. Lang. \\ Statistical analysis: R. R. Bailey. \\ Obtained funding: R. R. Bailey, C. E. Lang.
}

Financial Disclosures: The authors have declared that no competing interests exist.

Funding/Support: This material was based on work supported by the Washington University Institute of Clinical and Translational Sciences (grant UL1 TR000448) from the National Center for Advancing Translational Sciences of the National Institutes of Health (NIH). Additional NIH support included T32 HD7434-18, TL1 TR000449, and R01 HD068290.

Institutional Review: The protocol for the study was approved by the Washington University Institutional Review Board. All participants gave written consent prior to study participation.

Participant Follow-Up: The authors do not plan to inform participants of the publication of this study.

Disclaimer: The content is solely the responsibility of the authors and does not necessarily represent the official view of the NIH.

\section{REFERENCES}

1. Webster BS, Snook SH. The cost of compensable upper extremity cumulative trauma disorders. J Occup Med. 1994; 36(7):713-17. [PMID:7931735]

2. Zorowitz RD, Chen E, Tong KB, Laouri M. Costs and rehabilitation use of stroke survivors: A retrospective study of Medicare beneficiaries. Top Stroke Rehabil. 2009; 16(5):309-20. [PMID:19903649]

http://dx.doi.org/10.1310/tsr1605-309

3. Yelin E, Wanke LA. An assessment of the annual and longterm direct costs of rheumatoid arthritis: The impact of poor function and functional decline. Arthritis Rheum. 1999;42(6):1209-18. [PMID:10366114]

http://dx.doi.org/10.1002/15290131(199906)42:6<1209::AID-ANR18>3.0.CO;2-M

4. Fabrizio AJ. Work-related upper extremity injuries: prevalence, cost and risk factors in military and civilian populations. Work. 2002;18(2):115-21. [PMID:12441575]

5. Keogh JP, Nuwayhid I, Gordon JL, Gucer PW. The impact of occupational injury on injured worker and family: Outcomes of upper extremity cumulative trauma disorders in Maryland workers. Am J Ind Med. 2000;38(5):498-506. [PMID:11025491]

http://dx.doi.org/10.1002/10970274(200011)38:5<498::AID-AJIM2>3.0.CO;2-I

6. Baldwin ML, Butler RJ. Upper extremity disorders in the workplace: Costs and outcomes beyond the first return to work. J Occup Rehabil. 2006;16(3):303-23.

[PMID:16933145]

http://dx.doi.org/10.1007/s10926-006-9043-2

7. Pransky G, Benjamin K, Hill-Fotouhi C, Himmelstein J, Fletcher KE, Katz JN, Johnson WG. Outcomes in workrelated upper extremity and low back injuries: Results of a retrospective study. Am J Ind Med. 2000;37(4):400-409.

[PMID:10706752]

http://dx.doi.org/10.1002/(SICI)10970274(200004)37:4<400::AID-AJIM10>3.0.CO;2-C

8. Roger VL, Go AS, Lloyd-Jones DM, Benjamin EJ, Berry JD, Borden WB, Bravata DM, Dai S, Ford ES, Fox CS, Fullerton HJ, Gillespie C, Hailpern SM, Heit JA, Howard VJ, Kissela BM, Kittner SJ, Lackland DT, Lichtman JH, Lisabeth LD, Makuc DM, Marcus GM, Marelli A, Matchar DB, Moy CS, Mozaffarian D, Mussolino ME, Nichol G, Paynter NP, Soliman EZ, Sorlie PD, Sotoodehnia N, Turan TN, Virani SS, Wong ND, Woo D, Turner MB; American Heart Association Statistics Committee and Stroke Statistics Subcommittee. Heart disease and stroke statistics2012 update: A report from the American Heart Association. Circulation. 2012;125(1):e2-220. [PMID:22179539] http://dx.doi.org/10.1161/CIR.0b013e31823ac046

9. Pincus T, Callahan LF, Sale WG, Brooks AL, Payne LE, Vaughn WK. Severe functional declines, work disability, and increased mortality in seventy-five rheumatoid arthritis patients studied over nine years. Arthritis Rheum. 1984; 27(8):864-72. [PMID:6431998]

http://dx.doi.org/10.1002/art.1780270805

10. Rand D, Eng JJ. Disparity between functional recovery and daily use of the upper and lower extremities during subacute stroke rehabilitation. Neurorehabil Neural Repair. 2012;26(1):76-84. [PMID:21693771] http://dx.doi.org/10.1177/1545968311408918

11. Gross DP, Battié MC. Does functional capacity evaluation predict recovery in workers' compensation claimants with upper extremity disorders? Occup Environ Med. 2006; 63(6):404-10. [PMID:16551753] http://dx.doi.org/10.1136/oem.2005.020446

12. Uswatte G, Foo WL, Olmstead H, Lopez K, Holand A, Simms LB. Ambulatory monitoring of arm movement using accelerometry: An objective measure of upperextremity rehabilitation in persons with chronic stroke. Arch Phys Med Rehabil. 2005;86(7):1498-1501.

[PMID:16003690]

http://dx.doi.org/10.1016/j.apmr.2005.01.010

13. Uswatte G, Giuliani C, Winstein C, Zeringue A, Hobbs L, Wolf SL. Validity of accelerometry for monitoring realworld arm activity in patients with subacute stroke: Evidence from the extremity constraint-induced therapy evaluation trial. Arch Phys Med Rehabil. 2006;87(10):1340-45. 


\section{[PMID: 17023243]}

http://dx.doi.org/10.1016/j.apmr.2006.06.006

14. Uswatte G, Miltner WH, Foo B, Varma M, Moran S, Taub E. Objective measurement of functional upper-extremity movement using accelerometer recordings transformed with a threshold filter. Stroke. 2000;31(3):662-67.

[PMID:10700501]

http://dx.doi.org/10.1161/01.STR.31.3.662

15. Welk GJ, Schaben JA, Morrow JR Jr. Reliability of accelerometry-based activity monitors: A generalizability study. Med Sci Sports Exerc. 2004;36(9):1637-45. [PMID:15354049]

16. Welk GJ. Principles of design and analyses for the calibration of accelerometry-based activity monitors. Med Sci Sports Exerc. 2005;37(11, Suppl):S501-11.

[PMID:16294113] http://dx.doi.org/10.1249/01.mss.0000185660.38335.de

17. Lang CE, Wagner JM, Edwards DF, Dromerick AW. Upper extremity use in people with hemiparesis in the first few weeks after stroke. J Neurol Phys Ther. 2007;31(2):56-63. [PMID:17558358] http://dx.doi.org/10.1097/NPT.0b013e31806748bd

18. Seitz RJ, Hildebold T, Simeria K. Spontaneous arm movement activity assessed by accelerometry is a marker for early recovery after stroke. J Neurol. 2011;258(3):457-63. [PMID:20953792] http://dx.doi.org/10.1007/s00415-010-5778-y

19. van der Pas SC, Verbunt JA, Breukelaar DE, van Woerden $\mathrm{R}$, Seelen HA. Assessment of arm activity using triaxial accelerometry in patients with a stroke. Arch Phys Med Rehabil. 2011;92(9):1437-42. [PMID:21878214] http://dx.doi.org/10.1016/j.apmr.2011.02.021

20. Burdick KE, Endick CJ, Goldberg JF. Assessing cognitive deficits in bipolar disorder: Are self-reports valid? Psychiatry Res. 2005;136(1):43-50. [PMID:16024090] http://dx.doi.org/10.1016/j.psychres.2004.12.009

21. Adams SA, Matthews CE, Ebbeling CB, Moore CG, Cunningham JE, Fulton J, Hebert JR. The effect of social desirability and social approval on self-reports of physical activity. Am J Epidemiol. 2005;161(4):389-98. [PMID:15692083] http://dx.doi.org/10.1093/aje/kwi054

22. Kilbreath SL, Heard RC. Frequency of hand use in healthy older persons. Aust J Physiother. 2005;51(2):119-22. [PMID:15924514] http://dx.doi.org/10.1016/S0004-9514(05)70040-4

23. Michielsen ME, Selles RW, Stam HJ, Ribbers GM, Bussmann JB. Quantifying nonuse in chronic stroke patients: A study into paretic, nonparetic, and bimanual upper-limb use in daily life. Arch Phys Med Rehabil. 2012;93(11):1975-81. [PMID:22465403] http://dx.doi.org/10.1016/j.apmr.2012.03.016
24. Rand D, Eng JJ. Arm-hand use in healthy older adults. Am J Occup Ther. 2010;64(6):877-85. [PMID:21218678]

http://dx.doi.org/10.5014/ajot.2010.09043

25. Martínez-González MA, Martínez JA, Hu FB, Gibney MJ, Kearney J. Physical inactivity, sedentary lifestyle and obesity in the European Union. Int J Obes Relat Metab Disord. 1999;23(11):1192-1201. [PMID:10578210] http://dx.doi.org/10.1038/sj.ijo.0801049

26. Mokdad AH, Marks JS, Stroup DF, Gerberding JL. Actual causes of death in the United States, 2000. JAMA. 2004;291(10):1238-45. [PMID:15010446] http://dx.doi.org/10.1001/jama.291.10.1238

27. Yaffe K, Barnes D, Nevitt M, Lui LY, Covinsky K. A prospective study of physical activity and cognitive decline in elderly women: Women who walk. Arch Intern Med. 2001; 161(14):1703-8. [PMID:11485502] http://dx.doi.org/10.1001/archinte.161.14.1703

28. Penninx BW, Leveille S, Ferrucci L, van Eijk JT, Guralnik JM. Exploring the effect of depression on physical disability: Longitudinal evidence from the established populations for epidemiologic studies of the elderly. Am J Public Health. 1999;89(9):1346-52. [PMID:10474551]

http://dx.doi.org/10.2105/AJPH.89.9.1346

29. Fultz NH, Ofstedal MB, Herzog AR, Wallace RB. Additive and interactive effects of comorbid physical and mental conditions on functional health. J Aging Health. 2003; 15(3):465-81. [PMID:12914014] http://dx.doi.org/10.1177/0898264303253502

30. Rijken M, van Kerkhof M, Dekker J, Schellevis FG. Comorbidity of chronic diseases: Effects of disease pairs on physical and mental functioning. Qual Life Res. 2005; 14(1):45-55. [PMID:15789940] http://dx.doi.org/10.1007/s11136-004-0616-2

31. Caspersen CJ, Pereira MA, Curran KM. Changes in physical activity patterns in the United States, by sex and crosssectional age. Med Sci Sports Exerc. 2000;32(9):1601-9. [PMID:10994912] http://dx.doi.org/10.1097/00005768-200009000-00013

32. Hallal PC, Victora CG, Wells JC, Lima RC. Physical inactivity: Prevalence and associated variables in Brazilian adults. Med Sci Sports Exerc. 2003;35(11):1894-1900. [PMID:14600556] http://dx.doi.org/10.1249/01.MSS.0000093615.33774.0E

33. Michael YL, Berkman LF, Colditz GA, Kawachi I. Living arrangements, social integration, and change in functional health status. Am J Epidemiol. 2001;153(2):123-31.

[PMID:11159156]

http://dx.doi.org/10.1093/aje/153.2.123

34. Aday RH, Kehoe GC, Farney LA. Impact of senior center friendships on aging women who live alone. J Women Aging. 2006;18(1):57-73. [PMID:16635950] http://dx.doi.org/10.1300/J074v18n01 05 
35. Hull EE, Rofey DL, Robertson RJ, Nagle EF, Otto AD, Aaron DJ. Influence of marriage and parenthood on physical activity: a 2-year prospective analysis. J Phys Act Health. 2010;7(5):577-83. [PMID:20864752]

36. Aadahl M, Jørgensen T. Validation of a new self-report instrument for measuring physical activity. Med Sci Sports Exerc. 2003;35(7):1196-1202. [PMID:12840642] http://dx.doi.org/10.1249/01.MSS.0000074446.02192.14

37. Katzman R, Brown T, Fuld P, Peck A, Schechter R, Schimmel H. Validation of a short Orientation-Memory-Concentration Test of cognitive impairment. Am J Psychiatry. 1983;40(6):734-39. [PMID:6846631]

38. Heun R, Papassotiropoulos A, Jennssen F. The validity of psychometric instruments for detection of dementia in the elderly general population. Int J Geriatr Psychiatry. 1998; 13(6):368-80. [PMID:9658272] http://dx.doi.org/10.1002/(SICI)10991166(199806)13:6<368::AID-GPS775>3.0.CO;2-9

39. Andresen EM, Malmgren JA, Carter WB, Patrick DL. Screening for depression in well older adults: Evaluation of a short form of the CES-D (Center for Epidemiologic Studies Depression Scale). Am J Prev Med. 1994;10(2):77-84. [PMID:8037935]

40. Radloff LS. The CES-D scale: A self-report depression scale for research in the general population. Appl Psych Meas. 1977; 1:385-401. http://dx.doi.org/10.1177/014662167700100306

41. Shinar D, Gross CR, Price TR, Banko M, Bolduc PL, Robinson RG. Screening for depression in stroke patients: The reliability and validity of the Center for Epidemiologic Studies Depression Scale. Stroke. 1986;17(2):241-45. [PMID:3961834] http://dx.doi.org/10.1161/01.STR.17.2.241

42. Schwarz N, Oyserman D. Asking questions about behavior: Cognition, communication, and questionnaire construction. Am J Eval. 2001;22(2):127-60.

43. Cohen G, Java R. Memory for medical history: Accuracy of recall. Appl Cogn Psychol. 1995;9(4):273-88. http://dx.doi.org/10.1002/acp.2350090402
44. Cohen J. Statistical power analysis for the behavioral sciences, 2nd ed. Hillsdale (NJ): L. Erlbaum Associates; 1988.

45. Tatemichi TK, Desmond DW, Stern Y, Paik M, Sano M, Bagiella E. Cognitive impairment after stroke: frequency, patterns, and relationship to functional abilities. J Neurol Neurosurg Psychiatry. 1994;57(2):202-7.

[PMID:8126506] http://dx.doi.org/10.1136/jnnp.57.2.202

46. Roshanaei-Moghaddam B, Katon WJ, Russo J. The longitudinal effects of depression on physical activity. Gen Hosp Psychiatry. 2009;31(4):306-15. [PMID:19555789] http://dx.doi.org/10.1016/j.genhosppsych.2009.04.002

47. Bijnen FC, Feskens EJ, Caspersen CJ, Mosterd WL, Kromhout D. Age, period, and cohort effects on physical activity among elderly men during 10 years of follow-up: The Zutphen Elderly Study. J Gerontol A Biol Sci Med Sci. 1998; 53(3):M235-41. [PMID:9597057] http://dx.doi.org/10.1093/gerona/53A.3.M235

48. Troiano RP, Berrigan D, Dodd KW, Mâsse LC, Tilert T, McDowell M. Physical activity in the United States measured by accelerometer. Med Sci Sports Exerc. 2008;40(1): 181-88. [PMID:18091006] http://dx.doi.org/10.1249/mss.0b013e31815a51b3

Submitted for publication December 6, 2012. Accepted in revised form April 8, 2013.

This article and any supplementary material should be cited as follows:

Bailey RR, Lang CE. Upper-limb activity in adults: Referent values using accelerometry. J Rehabil Res Dev. 2013; 50(9):1213-22.

http://dx.doi.org/10.1682/JRRD.2012.12.0222

ResearcherID/ORCID: Ryan R. Bailey, MSOT, OTR/L: L-5559-2013

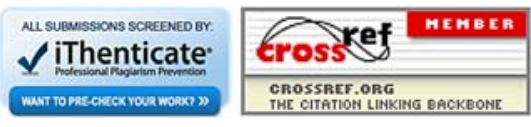

